\title{
Addiction to Tanning - A New Cause of Early Onset of Nonmelanoma Skin Cancer
}

\author{
Uwe Wollina*
}

\author{
Department of Dermatology and Allergology, Hospital Dresden-Friedrichstadt, Academic Teaching Hospital of the \\ Technical University of Dresden, Friedrichstrasse 41, D-1067 Dresden, Germany
}

\begin{abstract}
Basal cell carcinoma (BCC) is the most common non-melanoma skin cancer world wide. UV exposure plays a significant role in the pathogenesis of this tumor that is more common in older people. In the past, BCC in people younger than 30 years of age have been seen in connection with genetic diseases like Gorlin-Goltz syndrome. The histological type was mostly superficial and most common localization was on the trunk. Nowadays, frequent indoor tanning is a risk behavior that might lead to early development of facial and aggressive BCC in people younger than 30 years of age. This is illustrated by a case report of a 29-year old addictive indoor tanner, skin type I, who developed a solid BCC of the nose after more than 10 years of weekly tanning. Current health campaigns and preventive programs seem to be ineffective in this subgroup of patients. New strategies need to be developed.
\end{abstract}

Keywords: Non-melanoma skin cancer, basal cell carcinoma, frequent indoor tanning, UV-light exposure.

\section{INTRODUCTION}

The major motivation for tanning in the Western European and American World is related to aesthetic preference to a tanned skin related to physical fitness and youth [1]. This behavior is not shared by other cultures like Japan, India, China and the Arab countries where faint skin achieved by bleaching and avoidance of tanning might represent youth and wealth.

Tanning is a behaviour that is performed even in case the possible negative impact of UV-irradiation on health is well known such as UV-induced skin ageing and the induction of skin cancer [2]. This has led to the assumption that indoor tanning might have an addictive potency probably by induction of endogenous opioids [3-5].

In a recent critical review Nolan et al. (2009) stated that in some individuals tanning meets the criteria for a substance-related addictive disorder and frequent tanners show withdrawal symptoms [6]. These findings may have some impact on the strategies of preventive measures for this particular subgroup of consumers.

\section{CASE REPORT}

Our department is an academic teaching center with a skin cancer unit. Per year we see more than 1,000 skin cancer patients but during the last 5 years we have not seen a single patient with non-melanoma skin cancer (BCC and squamous cell cancer) in the age group below 30 without a genetic disease or underlying diseases that cause immunosuppression or need immunosuppressive therapy.

\footnotetext{
*Address correspondence to this author at the Department of Dermatology and Allergology, Hospital Dresden-Friedrichstadt, Academic Teaching Hospital of the Technical University of Dresden, Friedrichstrasse 41, D1067 Dresden, Germany; Tel: +49-351-4801685; Fax: +49-351-4801219; E-mail: Wollina-uw@khdf.de
}

Recently, a 29-year-old Caucasian woman presented with an ulcerated firm tumor on her nose tip that has been developed within the last 6 months. She was otherwise healthy and did not take any medications on a regular base. The family history was negative for tumor disorders or genetic disease and immunodeficiencies. She was working as a hair dresser. She did not perform outdoor sports. However, she reported to use indoor tanning for more than 10 years at least once a week.

On examination we found an otherwise healthy young woman, Fitzpatrick skin type I, white complexion, with multiple freckles and very mild elastosis of the skin of the face, neck and décolleté. On the tip of her nose was a firm ulcerated tumor of a diameter of about $5 \mathrm{~mm}$ (Fig. 1).

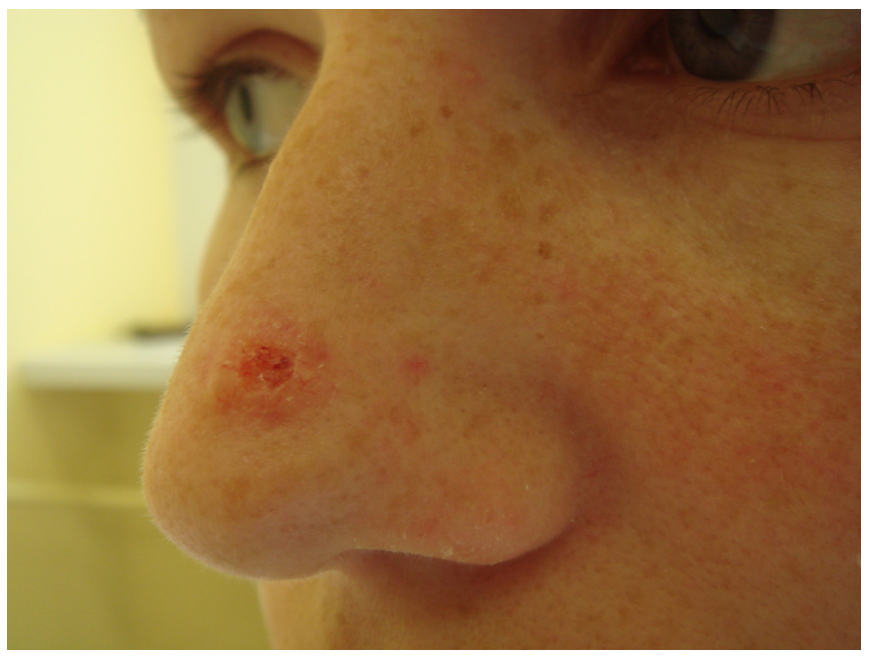

Fig. (1). Ulcerated basal cell carcinoma of the nose.

The tumor was completely removed by micrographically controlled surgery. Histopathology revealed a solid ulcerated basal cell carcinoma (BCC) (Fig. 2). Since she refused to 
give up her risky tanning behavior she got the advice to get a regular check-up for skin cancer.

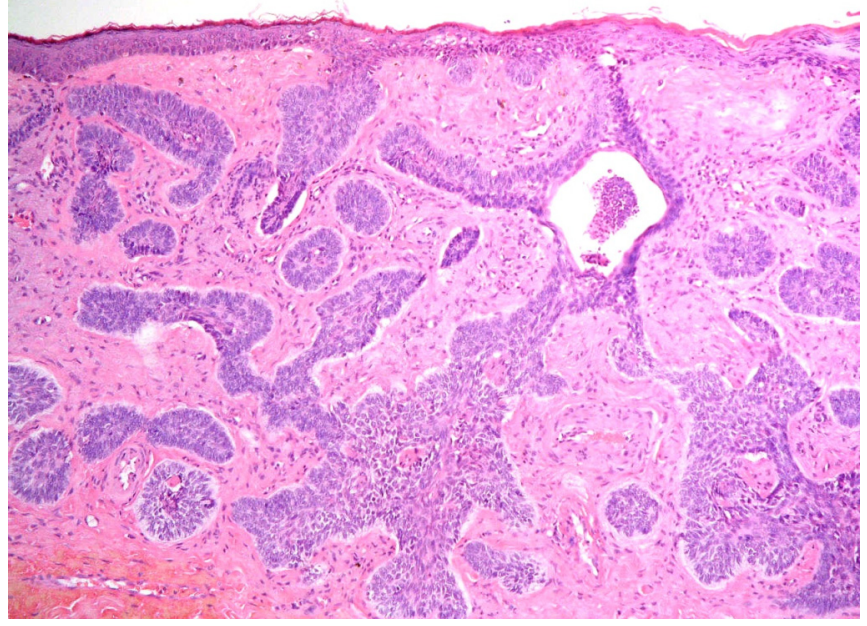

Fig. (2). Basal cell carcinoma of the nose, histology from the nonulcerated part showing typical basaloid cell proliferations (HE, $\mathrm{x}$ $10)$.

\section{DISCUSSION}

$\mathrm{BCC}$ is the most frequent malignant tumor of skin in Germany representing $80 \%$ of all nonmelanoma skin cancers. The age peak is between 65-69 years. The incidence is $67 / 100,000$ (males) and 45/ 100,000 (females). BCC most commonly occurs in adults, especially in the elderly population, although it rarely may be seen in children. Among this population, individuals with fair skin, blond or red hair, light eye color, poor tanning ability (skin type I) and with sun-damaged skin are more commonly affected. $\mathrm{BCC}$ is more common in men than in women and the maleto-female ratio is approximately 2:1 [7].

Although there is still an increase of non-melanoma skin cancer in Australia, the incidence in younger patients has stabilized due health care campaigns and prevention programs [8]. This has not been observed in either the Unites States or Europe.

In particular, chronic sun exposure appears to be important in the development of BCC. A latency period of 20-50 years is typically observed between the time of UV damage and clinical onset of BCC. The susceptibility for these kinds of tumors seems to be determined by a complex interaction between duration and intensity of exposure to ultraviolet radiation and specific polymorphic genes. In addition to the cumulative dose, the exposure to UV in different periods of life, especially exposure to the sun during childhood and adolescence, and pattern and amount of ultraviolet radiation seem to be even more critical for tumor development. In particular, individuals with fair skin, blond or red hair and light-colored eyes (skin type I), susceptible to sunburn and with a history of solar dermatitis in childhood or young adulthood, are exposed to the highest risk. Moreover, the risk of BCC development increases with intense intermittent amount of sun exposure when compared to an equal dose of continuous exposure [9].

In a population-based study in Bavaria (Germany) during the period 2001 until 2005 there was a significant association of work-related UV exposure and non-melanoma cancer risk. The risk of BCC was substantially elevated in male (RR, 2.9; 95\% CI, 2.2-3.9) and female (RR, 2.7; 95\% CI, 1.8-4.1) outdoor workers compared to male and female indoor workers, respectively [10].

Usually, younger ( $<40$ years of age) patients exhibited a lower prevalence of BCCs on the head and neck $(36.0 \% v s$ $57.3 \%, \mathrm{p}<.01)$ and a higher prevalence on the trunk $(59.3 \%$ vs $31.5 \%, \mathrm{p}<.01)$ and of superficial BCCs $(43.0 \%$ vs $31.5 \%$, $\mathrm{p}<.05)$ than older $(>90$ years $)$ patients. Superficial BCCs were mostly on the trunk, with a higher prevalence in younger patients $(86.5 \%$ vs $62.5 \%, \mathrm{p}<.05)$. Morpheic BCCs were mostly on the head and neck, and prevalence did not differ between age groups. Nodular BCCs were mostly on the head and neck in older patients [11].

The patient reported herein developed the tumor type most typically for older ages, a nodular BCC of the nose within a short period of time (about 6 months) and without the typical latency of BCC development after chronic UV exposure.

Frequent (indoor) tanners are a new group of patients developing skin cancer in younger age groups, as illustrated by the case report. Traditional health campaigns seem to have little if any impact on frequent tanner's risk behavior. In a study on US-American undergraduate students $(n=174)$, the relation between peer crowd identification and indoor tanning behavioral tendencies was examined. Results indicated peer crowd identification was significantly associated with indoor artificial UV tanning behavioral tendencies (attitudes, normative beliefs, past year use and intentions) independent of gender and skin type. Participants who identified with the popular peer crowd were at the greatest risk for indoor tanning UV exposure while identification with the brain crowd was protective against such behavior [12]. The findings have implications for future skin cancer intervention efforts in this group. In addition, other ways of consumer protection are discussed. The use of tanning saloons by youngsters has been criticized by the German Radiation Protection Agency [Bundesamt für Strahlenschutz (BfS)] [13] and a new law to prohibit the use of tanning salons by people younger than 18 is in preparation [14].

The dermatologist at least should advice such people a regular check-up for early detection of skin cancer if their behaviour cannot be modified.

\section{REFERENCES}

[1] Mackay H, Lowe D, Edwards D, Rogers SN. A survey of 14 to 16 year olds as to their attitude toward and use of sunbeds. Health Educ J 2007; 66: 141-52.

[2] Knight JM, Kirincich AN, Farmer ER, Hood AF. Awareness of the risks of tanning lamps does not influence behaviour among undergraduate college students. Arch Dermatol 2002; 138: 1311-5.

[3] Gambichler T, Bader A, Vojvodic M, et al. Plasma levels of opioid peptides after sunbed exposures. Br J Dermatol 2002; 147: 120711.

[4] Kaur M, Liguori A, Lang W, Rapp SR, Fleische AB Jr, Feldman SR. Induction of withdrawal-like symptoms in a small randomized, controlled trial of opioid blockade in frequent tanners. J Am Acad Dermatol 2006; 54: 709-11.

[5] Kaur M, Liguori A, Fleischer AB Jr, Feldman SR. Plasma endorphin levels in frequent and infrequent tanners before and after ultraviolet and non-ultraviolet stimuli. J Am Acad Dermatol 2006; 54: 919-20. 
[6] Nolan BV, Taylor SL, Liguori A, Feldman SR. Tanning as an addictive behaviour: a literature review. Photodermatol Photoimmunol Photomed 2009; 25: 12-9.

[7] Robert-Koch-Institut in Zusammenarbeit mit dem Statistischen Bundesamt: Hautkrebs. Gesundheitsberichterstattung des Bundes, Berlin 2004; Heft 22.

[8] Staples MP, Elwood M, Burton RC, Williams JL, Marks R, Giles GG. Non-melanoma skin cancer in Australia: the 2002 national survey and trends since 1985. Med J Aust 2006; 184: 6-10.

[9] Roewert-Huber J, Lange-Asschenfeldt B, Stockfleth E, Kerl H. Epidemiology and aetiology of basal cell carcinoma. Br J Dermatol 2007; 157(Suppl 2): 47-51.

[10] Radespiel-Tröger M, Meyer M, Pfahlberg A, Lausen B, Uter W, Gefeller O. Outdoor work and skin cancer incidence: a registry- based study in Bavaria. Int Arch Occup Environ Health 2009; 82: 357-63.

[11] Betti R, Radaelli G, Mussino F, Menni S, Crosti C. Anatomic location and histopathologic subtype of basal cell carcinomas in adults younger than 40 or 90 and older: any difference? Dermatol Surg 2009; 35: 201-6.

[12] Stapleton J, Turrisi R, Hillhouse J. Peer crowd identification and indoor artificial UV tanning behavioral tendencies. J Health Psychol 2008; 13: 940-5.

[13] Bundesamt für Strahlenschutz (BfS). Solarien gefährden die Gesundheit. Infoblatt March 2005 (http://www.bfs.de/de/bfs/druck/ infoblatt/Solarienbenutzung.html)

[14] Solarien gefährden Teenager. FOCUS Online Gesundheit, 03.05.2009 (www.focus.de/gesundheit/ratgeber/haut/news/hautkreb s-solarien-gefaehrden-teenager_aid_269037.html)

(C) Uwe Wollina; Licensee Bentham Open.

This is an open access article licensed under the terms of the Creative Commons Attribution Non-Commercial License (http://creativecommons.org/licenses/by$\mathrm{nc} / 3.0 /$ ) which permits unrestricted, non-commercial use, distribution and reproduction in any medium, provided the work is properly cited. 